\title{
A Novel Jasmonic Acid-Inducible Rice myb Gene Associates with Fungal Infection and Host Cell Death
}

\author{
Min-Woo Lee, Min Qi, and Yinong Yang \\ Department of Plant Pathology, 217 Plant Science Building, University of Arkansas, Fayetteville 72701, \\ U.S.A. \\ Accepted 21 December 2000.
}

\begin{abstract}
Endogenous signal molecules such as jasmonic acid (JA) and salicylic acid (SA) play an important role in induced resistance against pathogen infection and insect herbivory. In rice seedlings, $\mathrm{JA}$ is an effective inducer of systemic acquired resistance (SAR) against infection of blast fungus (Pyricularia grisea). To gain further insights into JAmediated defense signaling pathways, we isolated and characterized a pathogen- and JA-induced rice gene $(J A m y b)$ that encodes a Myb transcription factor. The JAmyb gene was induced within 1 day after fungal infection in resistant and susceptible interactions prior to lesion formation. Unlike most defense-related genes that are activated faster and stronger in resistant interactions, JAmyb induction by blast fungus is much higher in susceptible interactions, accompanied by large lesions and extensive tissue damage. Significant induction of JAmyb also was observed during cell death and lesion formation in certain lesion mimic mutants. Interestingly, JAmyb was activated rapidly by JA or wounding, independent of de novo protein synthesis, but not by other endogenous signal molecules such as SA and abscisic acid or SAR inducers such as benzothiadiazole and probenazole. We used SAdeficient transgenic plants to further demonstrate that depletion of $\mathrm{SA}$ in rice did not abolish but rather enhanced blast-induced JAmyb expression. These results suggest that JAmyb is related closely to host cell death and is involved in the JA-mediated, SA-independent signaling pathways in rice.
\end{abstract}

Additional keywords: disease susceptibility, hypersensitive response, plant defense response, rice blast fungus.

Pathogen-induced defense response in plants frequently is manifested by the development of a hypersensitive response (HR) and the subsequent establishment of systemic acquired resistance (SAR). The HR is a rapid defense response characterized by localized host cell death and necrosis at the infection site (Goodman and Novacky 1994). In contrast, SAR occurs throughout the entire plant (even in uninfected parts) and often provides long-lasting, broad-spectrum resistance against a variety of pathogens (Ryals et al. 1996). A large body of evidence has shown that salicylic acid (SA) is a key

Corresponding author: Y. Yang; Telephone: +1-501-575-5635; Fax: +1-501-575-7601; E-mail: yiyang@uark.edu endogenous secondary signal involved in the activation and/or potentiation of plant-defense responses (Dempsey et al. 1999). Ryals and coworkers (1996) used SA-deficient transgenic plants overexpressing a bacterial salicylate hydroxylase to demonstrate that SA is required for the establishment of SAR (Delaney et al. 1994; Gaffney et al. 1993). Recently, jasmonic acid (JA) also was demonstrated to play an important role in the induction of defense responses through a distinct, SAindependent signaling pathway (Dong 1998; Pieterse and Van Loon 1999; Reymond and Farmer 1998). For example, Arabidopsis mutants impaired in JA perception or biosynthesis are unable to deploy effective defense responses against pathogen infection (Penninckx et al. 1996; Thomma et al. 1998; Vijayan et al. 1998; Xie et al. 1998). Therefore, multiple endogenous molecules (including SA, JA, and ethylene) are involved in the complex network of signaling pathways that lead to local and systemic disease resistance. Furthermore, crosstalk between these defense signaling pathways appears to be very common and important in the regulation of plant defense responses (Reymond and Farmer 1998).

Although a complex network of signal transduction is involved in plant defense responses, many of defense signals such as SA and JA are probably integrated into a few terminal pathways that lead to the transcriptional activation of defense genes in the cell nucleus (Yang et al. 1997). As a result, SA-, JA-, or pathogen-activated transcription factors may play an important role in controlling defense gene expression and resistance responses. Currently, at least five major families of plant transcription factors, including bZIP, WRKY, EREBP, $\mathrm{Myb}$, and homeodomain proteins, have been shown to participate in the regulation of plant defense responses (Rushton and Somssich 1998). Most, if not all, of them were isolated from dicotyledonous plants. However, very little is known about defense-related transcription factors from monocotyledonous plants.

The Myb family of transcription factors is conserved structurally throughout eukaryotes, including animals, plants, and fungi (Lipsick 1996). Transcription factors encoded by animal $m y b$ genes are involved in cell cycling, proliferation, and differentiation. The $c-m y b$ gene, the cellular forebear of the $v$ $m y b$ oncogene from the avian myeloblastosis virus, is essential for the development of hematopoietic tissues, including the formation of lymphocytes and leukocytes important for the immune responses. Recently, animal Myb proteins also were demonstrated to participate in controlling apoptosis through the regulation of a new Myb target gene, $b c l-2$ (Oh and Reddy 
1999; Weston 1998). In plants, myb genes belong to a large multigene family (more than 100 members in Arabidopsis) (Kranz et al. 1998; Meissner et al. 1999) with very diverse functions (Jin and Martin 1999; Martin and Paz-Ares 1997). Plant $m y b$ genes are known to regulate the phenylpropanoid pathway (Grotewold et al. 1994; Moyano et al. 1996; PazAres 1987; Sablowski et al. 1994; Tamagnone et al. 1998), tryptophan biosynthesis (Bender and Fink 1998), cellular morphogenesis (Noda et al. 1994; Oppenheimer et al. 1991; Waites et al. 1998), hormone-responsive pathways, and abiotic stresses (Gubler et al. 1995; Hoeren et al. 1998; Iturriaga et al. 1996; Magaraggia 1997; Urao et al. 1993). Previously, it was shown that a tobacco $m y b$ gene is activated by tobacco mosaic virus (TMV) infection immediately preceding the $N$ resistance gene-mediated HR and SAR (Yang and Klessig 1996). This $m y b$ gene also is rapidly (within $15 \mathrm{~min}$ ) activated by SA treatment. Most recently, Arabidopsis $m y b$ genes were shown to be induced by bacterial pathogens (Daniel et al. 1999; Kranz et al. 1998). One of them, Atmyb30, was induced by an avirulent strain of Xanthomonas campestris pv. campestris and was related to programmed cell death in Arabidopsis lesion mimic mutants. To date, however, it is not known whether $m y b$ genes are induced by fungal infection and are involved in defense responses in monocotyledonous plants.

Here, we report on the isolation and characterization of a novel rice $m y b$ gene that is induced by the infection of blast fungus (Pyricularia grisea) during resistant and susceptible interactions. Expression of JAmyb also is associated closely with host cell death in certain lesion mimic mutants of rice plants. In contrast to the SA-inducible tobacco mybl gene, rice JAmyb expression is independent of SA but is mediated by JA, an effective inducer of SAR in rice.

\section{RESULTS}

\section{Cloning and sequence analysis of JAmyb from rice.}

In higher plants such as Arabidopsis, the $m y b$ gene family contains over 100 members that are induced differentially in response to various developmental and environmental cues (Kranz et al. 1998). To increase the probability of isolating pathogen-induced $m y b$ genes, mRNAs prepared from blast fungus-infected rice seedlings were used as templates for cDNA synthesis. Rice myb cDNA fragments (160 bp) were then amplified by polymerase chain reaction (PCR) with degenerate oligonucleotide primers designed according to the conserved domains of Myb proteins. Sequence analysis of 75 cloned myb fragments indicated the presence of five distinct groups (with DNA sequence identity ranging from 53 to $68 \%$ ) of rice $m y b$ genes. RNA blot analysis demonstrated that one group of $m y b$ genes was induced by blast fungus.

In order to isolate full-length $m y b$ genes, a rice cDNA library was constructed with mRNAs from leaves of blastinfected seedlings. Subsequent screening of the library led to the isolation of a full-length cDNA corresponding to the blastinduced $m y b$ gene. Because this $m y b$ gene was later shown to be activated specifically by JA, it was designated JAmyb. The $J A m y b$ cDNA is $1,343 \mathrm{bp}$ in length and contains a 126-bp $5^{\prime}$ untranslated sequence and a 359-bp $3^{\prime}$ untranslated region with a typical polyadenylation signal (Fig. 1). The predicted open reading frame encodes a full-length protein of 285 amino acid residues, with an estimated molecular mass of $32.8 \mathrm{kDa}$.
The hydrophilic JAMyb protein has a calculated isoelectric point of 5.74. Sequence analysis reveals that JAMyb contains two imperfect tryptophan repeats (R2 and R3) in the Nterminal conserved region, which is characteristic of most plant Myb transcription factors. Furthermore, secondary structure analysis of JAmyb predicts that the tryptophan repeats form helix-turn-helix (H-T-H) DNA-binding motifs. Similar to many animal and plant Myb transcription factors, JAMyb also contains a potential ATP-GTP-binding site (Ploop), a redox-sensitive cysteine, and a nuclear localization sequence in the N-terminal DNA-binding domain. In contrast to the H-T-H motifs in the basic DNA-binding domain, the acidic C-terminal region of JAMyb forms amphipathic $a$ helices, which are characteristic of a transcriptional activation domain.

A database search indicated that the $\mathrm{N}$-terminal, putative DNA-binding domain of JAMyb is highly similar to that of animal and plant Myb proteins. The C-terminal region of JAmyb is distinct and shares no significant homology with other plant Myb proteins, although short stretches of homologous sequences were found in several plant Myb proteins, including CpMyb5, CpMyb7, and CpMyb10 of Craterostigma plantagineum; GhMyb of cotton; NtMyb1 of tobacco; THM18 of tomato; PhMyb of petunia; and AtMyb2 of Arabidopsis. Phylogenetically, JAMyb is not the most closely related to the other 12 rice Myb proteins found in the database (Fig. 2). Rather, it is most closely related to C. plantagineum Myb proteins and Arabidopsis AtMyb2, both of which are induced by abscisic acid (ABA) and/or dehydration.

To determine the copy number of JAmyb, rice genomic DNA was digested with EcoRI and HindIII, respectively, and probed with the gene-specific $3^{\prime}$ region (position 550 to 1,343 bp) of JAmyb cDNA. Southern blot analysis revealed single hybridizing fragments (12 and $2 \mathrm{~kb}$ for EcoRI and HindIII enzyme digests, respectively), indicating that JAmyb is a single-copy gene in rice.

\section{Induction of JAmyb by blast infection precedes lesion formation.}

An avirulent blast isolate and its virulent mutant were used to elicit resistant and susceptible interactions, respectively, on rice cultivar Drew (Oryza sativa spp. japonica). Because the virulent strain is a race-change mutant of the avirulent isolate (Harp and Correll 1998), they are basically isogenic and likely differ only in the presence or absence of avirulence gene(s). The avirulent isolate typically elicits HR on Drew, resulting in small, reddish-brown lesions, whereas the virulent racechange mutant elicits large, diamond-shape lesions. To analyze the expression pattern of JAmyb in response to blast infection, RNA blots prepared from mock- and blast-infected rice leaves were probed with the $3^{\prime}$ gene-specific region (550 to $1,343 \mathrm{bp}$ ) of $J A m y b$. In addition, the same blots were probed with the cDNA of $P B Z 1$, a rice defense gene encoding an intracellular PR-10 protein (Midoh and Iwata 1996). RNA blot analyses indicated that JAmyb is expressed at very low levels in the mock-inoculated leaves of rice plants but is significantly induced by avirulent and virulent isolates of blast fungus in resistant and susceptible reactions (Fig. 3). The $J A m y b$ gene was induced within 1 day, continuously increasing 4 days postinoculation in blast-infected leaves. The levels of JAmyb expression appear to be higher in the susceptible 
reaction than in the resistant reaction. In contrast, induction of PBZ1 was faster and lasted longer in the resistant reaction than in the susceptible reaction.

\section{Expression of JAmyb is associated}

\section{with host cell death in lesion mimic mutants.}

Because $J A m y b$ expression is associated with blast fungusinduced cell death during resistant and susceptible reactions, we wanted to know whether JAmyb also is related to programmed cell death that occurs during lesion formation in rice lesion mimic plants. Three lesion mimic mutants of rice were tested, including two Sekiguchi lesion mutants (B689A-sl and
Labelle-sl) and a purplish-brown lesion mutant (Labelle- $p b l$ ) (Marchetti et al. 1983). B689A-sl and Labelle-sl are allelic to the Sekiguchi mutation and exhibit reddish-brown lesions. The $s l$ mutation causes much larger lesions and more extensive cell death than the $p b l$ mutation. RNA blot analysis indicated that $J A m y b$ was expressed only in lesioned parts of the leaf but not in nonlesioned parts, suggesting that JAmyb expression was associated closely with localized cell death (Fig. 4). There is a distinct difference between the Sekiguchi mutants and the purplish-brown lesion mutant in terms of JAmyb expression levels during lesion formation. Much stronger induction of JAmyb was observed in B689A-sl and Labelle-sl

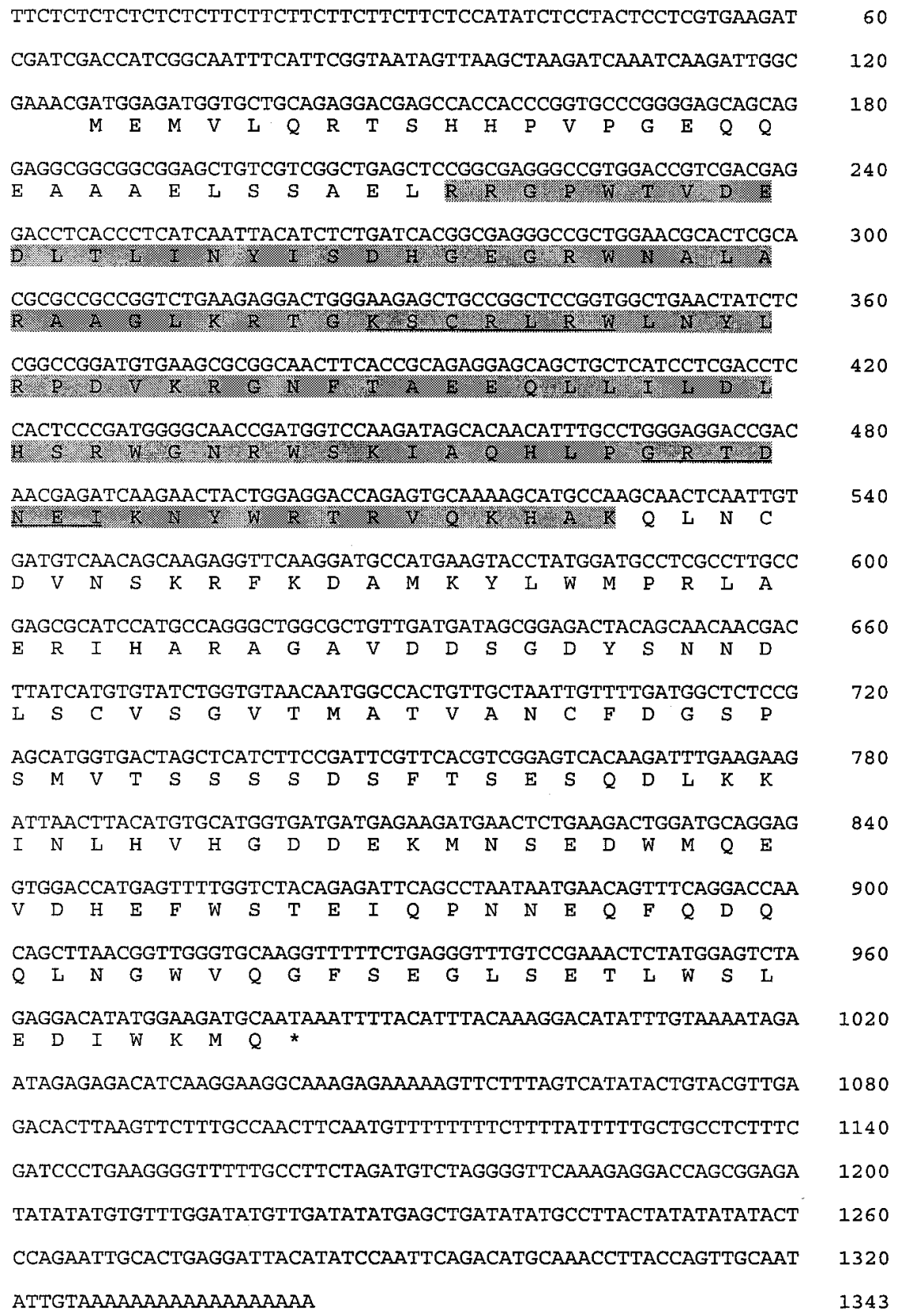

Fig. 1. Nucleotide and deduced amino acid sequences of rice JAmyb cDNA (GenBank accession no. AY026332). The shaded amino acid sequence represents the conserved DNA-binding domain containing two imperfect tryptophan repeats (R2 and R3) that are characteristic of most plant Myb transcription factors. The underlined sequences were used to design degenerate primers for the amplification of 160-bp polymerase chain reaction fragments of rice $m y b$ genes. 
(large, brown lesions) than in Labelle-pbl (small, purplish lesions). In contrast, $P B Z 1$ expression levels were about the same in the lesioned parts of all three mutants (Fig. 4).

\section{Expression of $J A m y b$ is independent of salicylic acid.}

SA and JA are the most important endogenous signals mediating transcriptional activation of defense-related genes and host defense response. To place JAmyb in a particular signal-

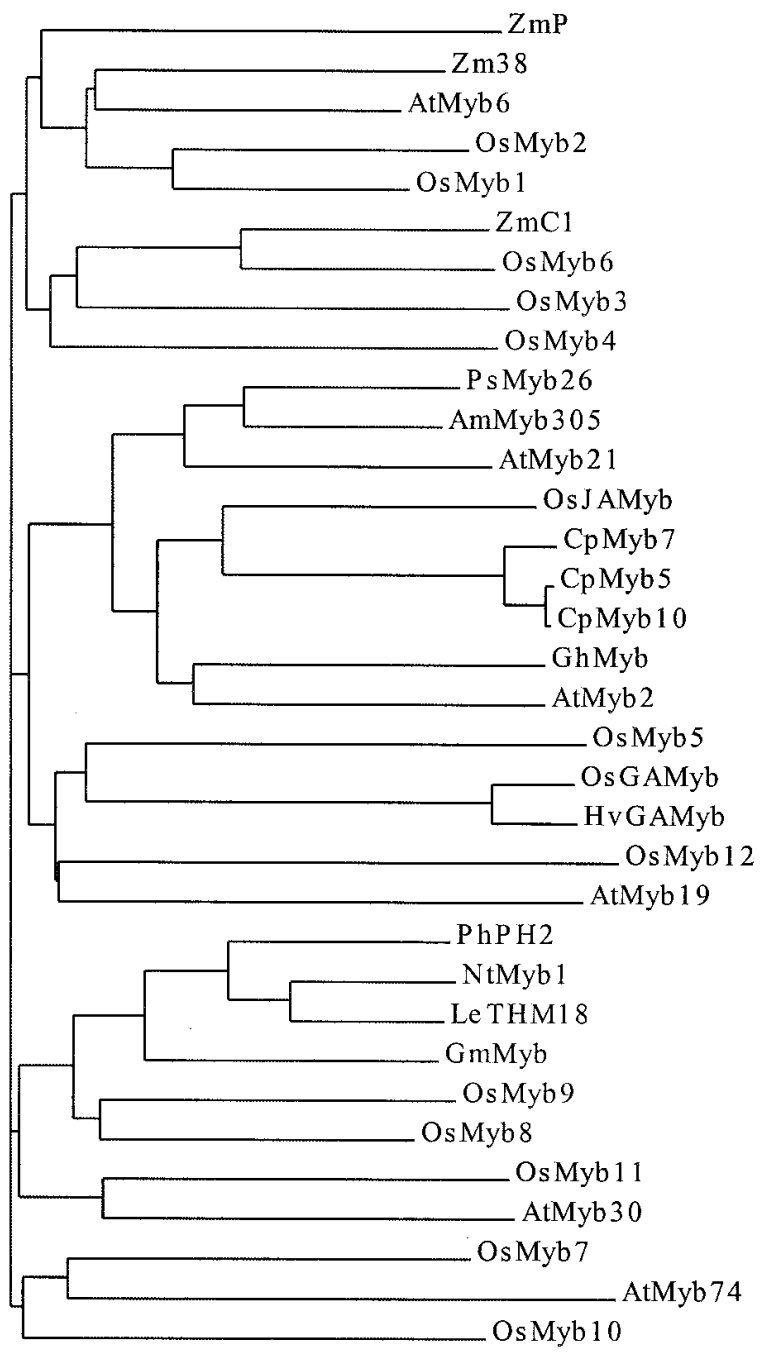

Fig. 2. The relationship between rice JAMyb and other plant Myb proteins. The dendrogram was generated based on the multiple sequence alignment of the following Myb proteins: ZmP, Zea mays, U57002; Zm38, Z. mays, P20025; AtMyb6, Arabidopsis thaliana, U26936; OsMyb2, Oryza sativa, D88618; OsMyb1, O. sativa, D88617; ZmC1, Z. mays, P10290; OsMyb6, O. sativa, Y15219; OsMyb3, O. sativa, D88619; OsMyb4, O. sativa, D88620; PsMyb26, Pisum sativum, Y11105; AmMyb305, Antirrhinum majus, JQ0958; AtMyb21, A. thaliana, AF062870; OsJAMyb, O. sativa; CpMyb7, Craterostigma plantagineum, U33917; CpMyb5, C. plantagineum, U33916; CpMyb10, C. plantagineum, U33915; GhMyb, Gossypium nirsutum, AF034133; AtMyb2, A. thaliana, D14712; OsMyb5, O. sativa, D88621; OsGAMyb, O. sativa, X98355; HvGAMyb, Hordeum vulgare, X87690; OsMyb12, O. sativa, AF172282; AtMyb19, A. thaliana, AF062868; PhPH2, Petunia hybrida, S26604; NtMyb1, Nicotiana tabacum, U72762; LeTHM18, Lycopersicon esculentum, T07395 GmMyb, Glycine max, AB029159; OsMyb9, O. sativa, Y11350; OsMyb8, O. sativa, Y11414; OsMyb11, O. sativa, Y11352; AtMyb30, A. thaliana, AF062873; OsMyb7, O. sativa, Y11415; AtMyb74, A. thaliana, AF062907; OsMyb10, O. sativa, Y11351. ing pathway, we examined the expression pattern of JAmyb with SA-deficient transgenic rice that was generated by overexpression of a bacterial salicylate hydroxylase (encoded by $n a h G$ of Pseudomonas putida). These NahG plants contain less than $0.1 \mu \mathrm{g}$ of SA per $\mathrm{g}$ fresh weight, which is two orders of magnitude lower than the normal SA level (5 to $30 \mu \mathrm{g}$ per $\mathrm{g}$ fresh weight in rice, and exhibit increased susceptibility to blast infection, as indicated by larger lesions and more extensive tissue damage (Yang and Qi 2000). Homozygous transgenic lines carrying the $n a h G$ transgene were infected with an avirulent blast isolate and analyzed for JAmyb induction. Surprisingly, depletion of SA did not reduce but significantly increased blast-induced $J A m y b$ expression as well as cell death and tissue damage in NahG plants (Fig. 5). This result not only demonstrates that $J A m y b$ induction is independent of the SA defense pathway, but further confirms that high-level expression of JAmyb is associated with large lesions and extensive cell death/tissue damage.

\section{Specific and rapid activation of JAmyb by jasmonic acid or wounding.}

To further evaluate the effect of signal molecules on JAmyb expression, SA, JA, benzothiadiazole (BTH, an analog of $\mathrm{SA}$ ), probenazole (PBZ, a fungicide capable of inducing SAR in rice), ABA, and wounding were applied individually to 2week-old rice seedlings. RNA blot analyses show that JAmyb was rapidly activated (within $1 \mathrm{~h}$ ) by JA, peaked at $2 \mathrm{~h}$, and decreased at $4 \mathrm{~h}$ after treatment (Fig. 6). The expression of $J A m y b$ also was induced at $2 \mathrm{~h}$ after wounding, a process that could lead to production of JA. JAmyb, however, was not activated by $\mathrm{SA}, \mathrm{BTH}, \mathrm{PBZ}$, or $\mathrm{ABA}$. In comparison, $P B Z 1$ was induced in rice seedlings by all five chemicals. In rice-cell suspension cultures, JA rapidly induced (within $30 \mathrm{~min}$ ) $J A m y b$, which was undetectable under normal tissue culture conditions or by treatment of ABA, SA, BTH, or PBZ (Fig. 7). JA and BTH also induced $P B Z 1$ in cell suspension cultures. In contrast to its activation in seedlings, $P B Z 1$ was not induced by $\mathrm{SA}, \mathrm{ABA}$, or $\mathrm{PBZ}$ in suspension cells, indicating differential expression of $P B Z 1$ in seedlings versus cell suspension cultures.

\section{Effect of cycloheximide on JAmyb expression.}

The rapid activation of JAmyb by JA suggests that its induction might not require de novo protein synthesis. To investigate this possibility, protein synthesis was inhibited by pretreatment of rice plants with cycloheximide $(\mathrm{CHX})$ at $30 \mathrm{~min}$

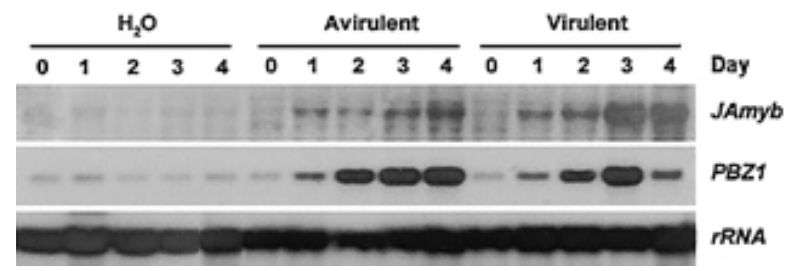

Fig. 3. Induction of JAmyb by blast fungus during resistant and susceptible interactions. Total RNAs were isolated from rice seedlings following infection with an avirulent isolate (resistant interaction) and its virulent race-change mutant (susceptible interaction). The RNA blot was sequentially probed with the cDNA fragments of rice JAmyb and PBZ1. The same blot also was probed with a rice $25 \mathrm{~S} r D N A$ fragment as loading control. 
before treatment of JA. RNA blot analysis showed that CHX did not block JA-mediated activation of JAmyb (Fig. 8). CHX treatment alone, however, induced JAmyb and enhanced $J A m y b$ expression synergistically when combined with JA. Similar results were reported with tobacco mybl and barley GAmyb expression in response to $\mathrm{CHX}$ treatment. In contrast to JAmyb, induction of $P B Z 1$ by JA was blocked by CHX treatment, suggesting that $P B Z 1$ expression is dependent upon the synthesis of new proteins.

\section{DISCUSSION}

Endogenous plant molecules such as SA and JA are known to mediate complex defense signaling pathways that lead to the transcriptional activation of defense genes. Therefore, SAor JA-induced plant transcription factors are likely to be involved in the regulation of defense gene expression and induction of local and systemic resistance. Previously, a TMVand SA-induced tobacco gene encoding a Myb transcription factor was shown to participate in $N$ gene-mediated HR and SAR (Yang and Klessig 1996). At least two Arabidopsis myb genes also were induced by bacterial infection and/or related to hypersensitive cell death (Daniel et al. 1999; Kranz et al. 1998). In this study, we demonstrated for the first time the induction of a plant $m y b$ gene by fungal infection. To our knowledge, JAmyb also is the first JA-induced transcription factor gene isolated from monocotyledonous plants. Most recently, JA-induced APETALA2 (AP2)-domain transcription factors were isolated from periwinkle and shown to participate in the regulation of primary and secondary metabolism (Menke et al. 1999; Van der Fits and Memelink 2000).

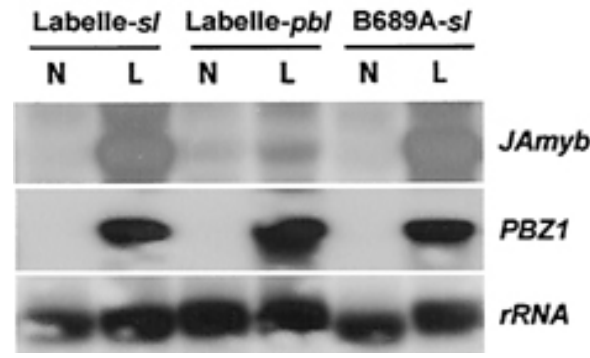

Fig. 4. Expression of JAmyb during lesion formation in rice lesion mimic mutants. Total RNAs were isolated from nonlesion (N, leaf segments without lesions) and lesion ( $\mathrm{L}$, leaf segments with lesions) parts of rice leaves. B689A-sl and Labelle-sl carry the Sekiguchi mutation and exhibit reddish-brown lesions. Labelle-pbl is not allelic to the Sekiguchi mutation and exhibits purplish-brown lesions.

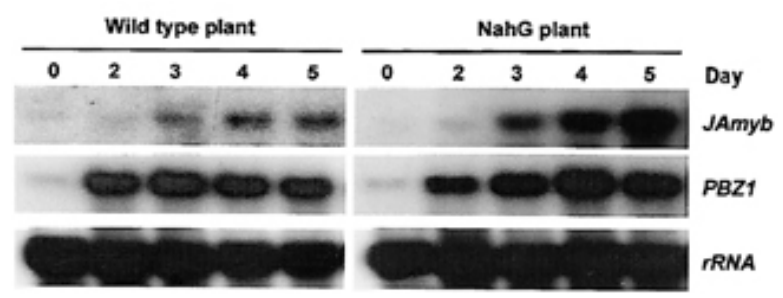

Fig. 5. Increased induction of JAmyb by blast fungus in SA-deficient transgenic rice. NahG plants are from homozygous transgenic lines carrying the bacterial salicylate hydroxylase transgene. Wild-type plants are from segregation lines that lost $n a h G$ transgene. RNA samples were prepared from rice seedlings infected with an avirulent blast isolate and probed sequentially with rice $J A m y b, P B Z 1$, and $r D N A$ cDNAs.
The JAmyb gene encodes a novel rice protein with a distinct $\mathrm{C}$-terminal region as well as a conserved $\mathrm{N}$-terminal region containing tryptophan repeats characteristic of the Myb family. Phylogenetically, JAMyb is related most closely to the proteins encoded by the ABA-inducible $m y b$ genes of $C$.
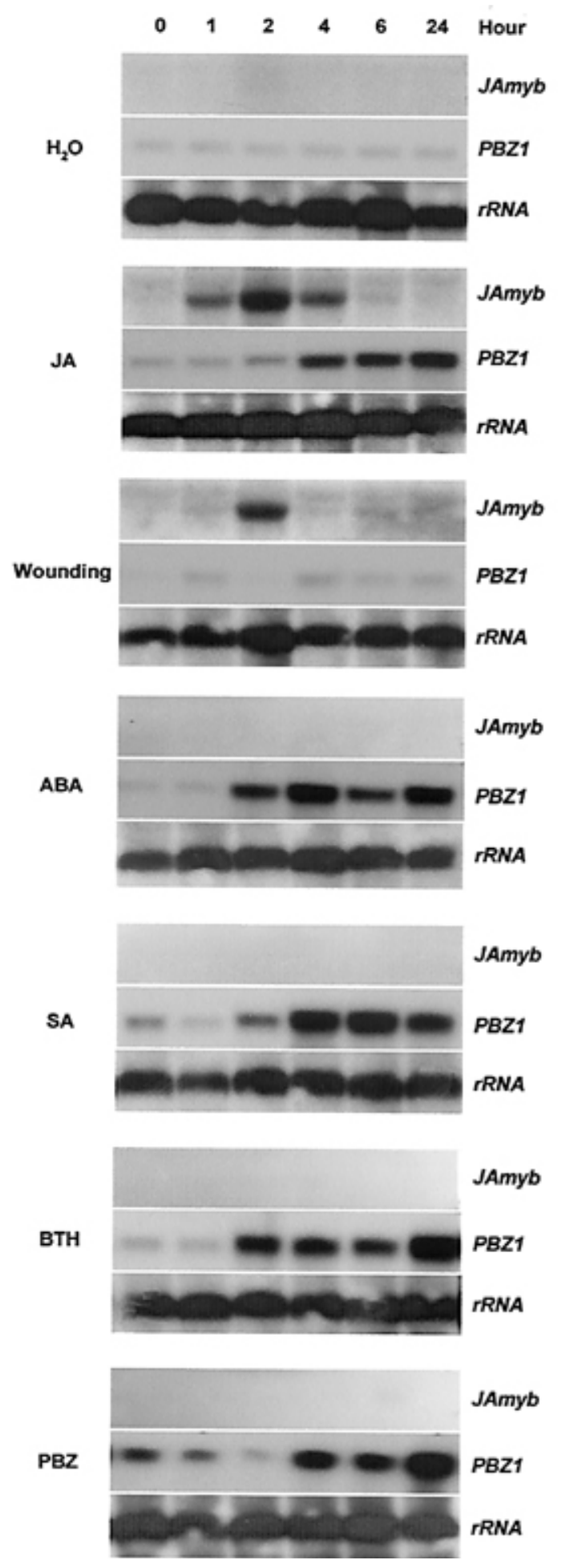

Fig. 6. Specific induction of Jamyb by jasmonic acid (JA) or wounding in rice seedlings. Total RNAs were isolated from rice leaves treated with $\mathrm{H}_{2} \mathrm{O}$, JA $(0.1 \mathrm{mM})$, abscisic acid $(0.1 \mathrm{mM})$, salicylic acid $(1.5 \mathrm{mM})$, benzothiadiazole $(0.25 \mathrm{mM})$, probenazole $(0.25 \mathrm{mM})$, and wounding. 
plantagineum (CpMyb5, 7, and 10) and Arabidopsis thaliana (Atmyb2), rather than those encoded by pathogen-inducible $m y b$ genes (mybl, Atmyb19, and Atmyb30) or known rice myb genes. Despite its closest homology with ABA-induced $m y b$ genes, however, pathogen-induced $J A m y b$ is activated transiently by JA or wounding but not by ABA, SA, BTH, or PBZ in seedlings and cell cultures. This result is not unexpected because previous studies have shown that function or speci-
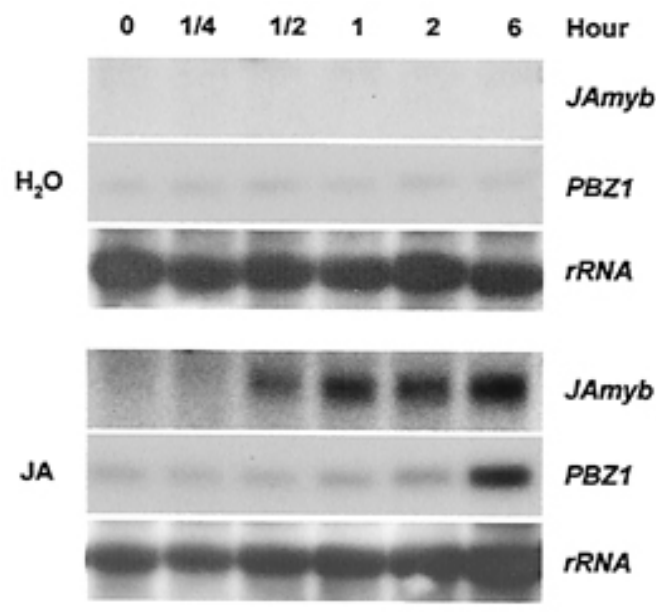

JAmyb

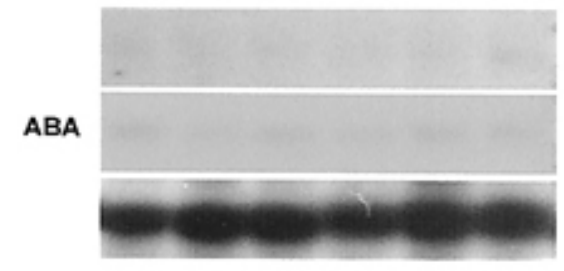

JAmyb

PBZ1

rRNA
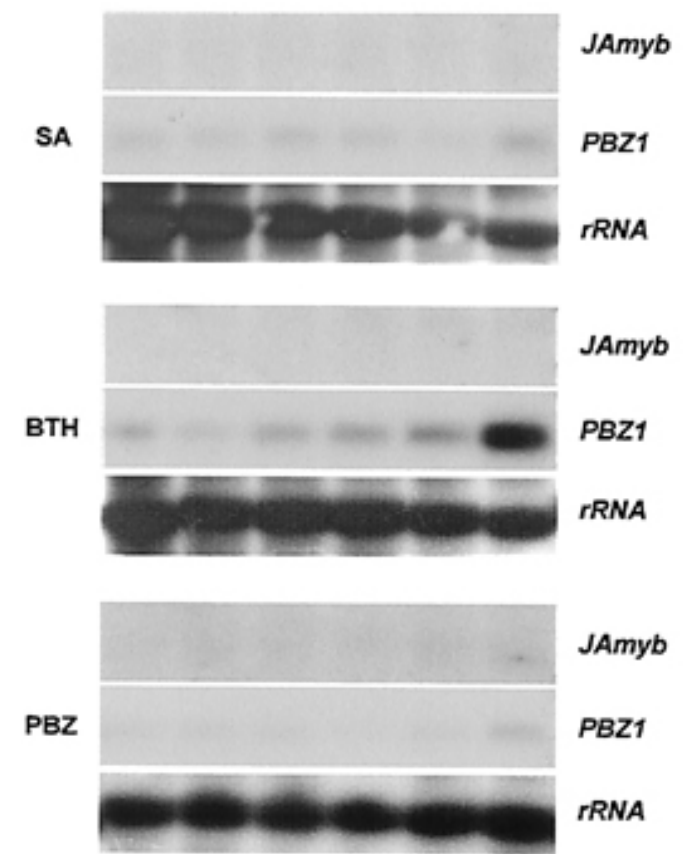

Fig. 7. Specific induction of Jamyb by jasmonic acid (JA) in rice cell suspension cultures. Total RNAs were isolated from cell-suspension cultures treated with $\mathrm{H}_{2} \mathrm{O}$, JA $(0.02 \mathrm{mM})$, abscisic acid $(0.02 \mathrm{mM})$, salicylic acid $(0.5 \mathrm{mM})$, benzothiadiazole $(0.05 \mathrm{mM})$, and probenazole $(0.05 \mathrm{mM})$ ficity of plant $m y b$ genes is not necessarily correlated with their position in the phylogeny (Rosinski and Atchley 1998). Moreover, jasmonate signaling can be uncoupled from ABA signaling (Lee et al. 1996).

JA is a 12-carbon fatty-acid derivative produced from the major plant plasma membrane lipid linolenic acid via the octadecanoid biosynthetic pathway. In addition to its wellknown role in signaling induced insect resistance, there have been increasing reports demonstrating the importance of JA in mediating defense responses against plant pathogens, particularly fungi (Dong 1998; Reymond and Farmer 1998). In rice, JA appears to be a major endogenous molecule mediating phytoalexin production and SAR (Schweizer et al. 1998; Tamogami et al. 1997; Y. Yang, unpublished data). We used SA-deficient transgenic rice to show that blast fungus-induced $J A m y b$ expression was independent of the SA signaling pathway. JAmyb, however, is induced specifically by wounding or JA and may encode a component of the rice JA signaling pathway. The specific and rapid activation of JAmyb by wounding or JA also is consistent with the distinct feature of the blast-infection process. Under our experimental conditions, fungal spore germination and appressorium formation occur within $12 \mathrm{~h}$ postinoculation. It is well known that blast appressoria penetrate rice epidermis by generating enormous turgor pressure that allows a penetration peg to rupture the underlying cuticle. Therefore, the early activation of JAmyb by blast fungus may result from mechanical force and wounding associated with the infection process.

In contrast to tobacco mybl, which is activated by viral infection only during the HR, JAmyb was induced by blast fungus in resistant and susceptible interactions. These differences in $m y b$ gene expression may be explained by the uniqueness of each pathosystem. In the tobacco-TMV system, viral infection of a resistant cultivar carrying the $N$ resistance gene results in SA induction, defense gene expression, and hypersensitive cell death, whereas infection of a susceptible cultivar leads to the development of mosaic symptoms but not defense gene induction or host cell death. It is likely that TMV may have actively suppressed defense gene activation and host cell death to favor its own reproduction and spread in tobacco plants. In the rice- $P$. grisea system, infection with the avirulent pathogen results in rapid but limited hypersensitive cell death, whereas the virulent isolate causes slower but more extensive host cell death and tissue damage. In such a pathosystem, we found that many defense-related genes induced by an avirulent blast pathogen during race-specific resistance responses also are activated by a virulent isolate during the susceptible interaction (Y. Yang, unpublished data). Therefore, host defense responses may have been activated (at different levels of strength) by avirulent and virulent pathogens through common defense signaling pathways.

Induction of $J A m y b$ occurs within 1 day postinoculation of either avirulent or virulent blast isolates, thus preceding the formation of visible blast lesions. Surprisingly, induction of $J A m y b$ is stronger and lasts longer in the susceptible reaction than in the resistant reaction. In NahG plants, increased susceptibility (indicated by extensive cell death-tissue damage and increased fungal growth) to avirulent blast isolates also was associated with significantly enhanced expression of $J A m y b$. This pattern of gene expression clearly is different from most, if not all, of the previously reported defense- 
related genes that typically exhibit faster and stronger induction in resistant interactions than in susceptible interactions (e.g., $P B Z 1$ induction by an avirulent pathogen is stronger and lasts longer than by a virulent pathogen [Fig. 3]). As mentioned below, one possibility is that JAmyb encodes a positive regulator of cell death; therefore, the higher the expression level of JAmyb, the more extensive cell death/tissue damage in the susceptible reaction. Another possibility is that JAmyb gene may participate in the signaling and regulation of susceptible responses in rice plants.

In addition to its activation during the blast-induced cell death, the involvement of JAmyb in host cell death has been demonstrated further with rice lesion mimic mutants. Previous studies have shown that lesion mimic mutants produce spontaneous lesions that are phenotypically similar to hypersensitive cell death triggered by blast infection (Takahashi et al. 1999). The $J A m y b$ gene is activated only in the lesion part, not in the healthy part of rice leaves. In contrast to $P B Z 1$, which has a similar level of activation during lesion formation in all mutants, induction of JAmyb is very strong in Sekiguchi mutants (with large lesions and extensive cell death/tissue damage) but very weak in the purplish-brown lesion mutant (with small lesions and limited tissue damage), suggesting that $J A m y b$ likely is involved in the cell-death pathway controlled by Sekiguchi mutation. Recently, animal Myb proteins have been shown to act as a regulator of programmed cell death through regulation of its target gene, $b c l-2$ (Weston 1998). In plants, tobacco mybl and Arabidopsis Atmyb30 are related to hypersensitive cell death (Daniel et al. 1999; Yang and Klessig 1996). Our data suggest that JAmyb also is related to the cell death process induced by blast infection or Sekiguchi mutation. Because JAmyb activation precedes the HR and blast lesion formation, it may act as a transcriptional regulator of signaling pathway(s) leading to host cell death. To test this hypothesis, we recently generated transgenic rice lines overexpressing the JAmyb transgene. Preliminary analysis indicates that overexpression of JAmyb led to lesion formation in the leaves of transgenic plants (M.-W. Lee and Y. Yang, unpublished data). In addition to its potential role in cell death, $J A m y b$ also may participate in transcriptional regulation of phytoalexin biosynthetic genes because plant $m y b$ genes are known to regulate the phenylpropanoid pathway, and JA was shown to activate biosynthetic genes involved in the production of flavonoid phytoalexins in rice (Tamogami et al. 1997). At present, we have not yet identified JAmyb's target genes and their biological function. Apparently, in vitro and in vivo analyses (e.g., trans-factor-cis-element interaction, overexpression, gene silencing, and/or knockout mutation) are required to help elucidate the role of JAmyb in rice defense responses.

\section{MATERIALS AND METHODS}

\section{Plant materials and fungal isolates.}

Seeds of rice cultivar Drew were germinated and grown in a growth room at $28^{\circ} \mathrm{C}$ under $16 \mathrm{~h}$ of light for 2 weeks before being used in experiments. Rice lesion mimic mutants (B689A-sl, Labelle-sl, and Labelle-pbl) were grown under the same conditions as described above. The SA-deficient transgenic rice was generated by overexpression of bacterial $n a h G$ gene via Agrobacterium-mediated transformation (Yang and
Qi 2000). Homozygous transgenic lines were selected by Southern blots and segregation analyses. To obtain cellsuspension cultures, rice callus was initiated first from Drew seeds on N6 solid medium (Chu et al. 1975) supplemented with $2 \mathrm{mg}$ of 2,4-dichlorophenoxyacetic acid per liter. Subsequently, seed-derived callus was transferred into N6 liquid medium. Cell suspension cultures were grown at $28^{\circ} \mathrm{C}$ and subcultured weekly. The fungal isolates used in this study belong to the IC-17 pathotype of $P$. grisea. The wild-type isolate is avirulent on Drew, but its race-change mutant is virulent on the same cultivar (Harp and Correll 1998).

\section{Pathogen inoculation and chemical treatments.}

Fungal inoculation of rice plants was carried out by spraying with $P$. grisea at a concentration of 750,000 spores per $\mathrm{ml}$. After incubation in a dew chamber $\left(22^{\circ} \mathrm{C}\right)$ for $24 \mathrm{~h}$, plants were moved to a growth chamber and maintained at $28^{\circ} \mathrm{C}$ under $16 \mathrm{~h}$ of light. For chemical treatments, 2-week-old rice seedlings were sprayed with either SA $(1.5 \mathrm{mM})$, JA $(0.1$ $\mathrm{mM})$, BTH $(0.25 \mathrm{mM}), \mathrm{PBZ}(0.25 \mathrm{mM})$ or ABA $(0.1 \mathrm{mM})$. In $\mathrm{CHX}$ tests, leaves were pretreated with $\mathrm{CHX}(0.3 \mathrm{mM})$ at 30
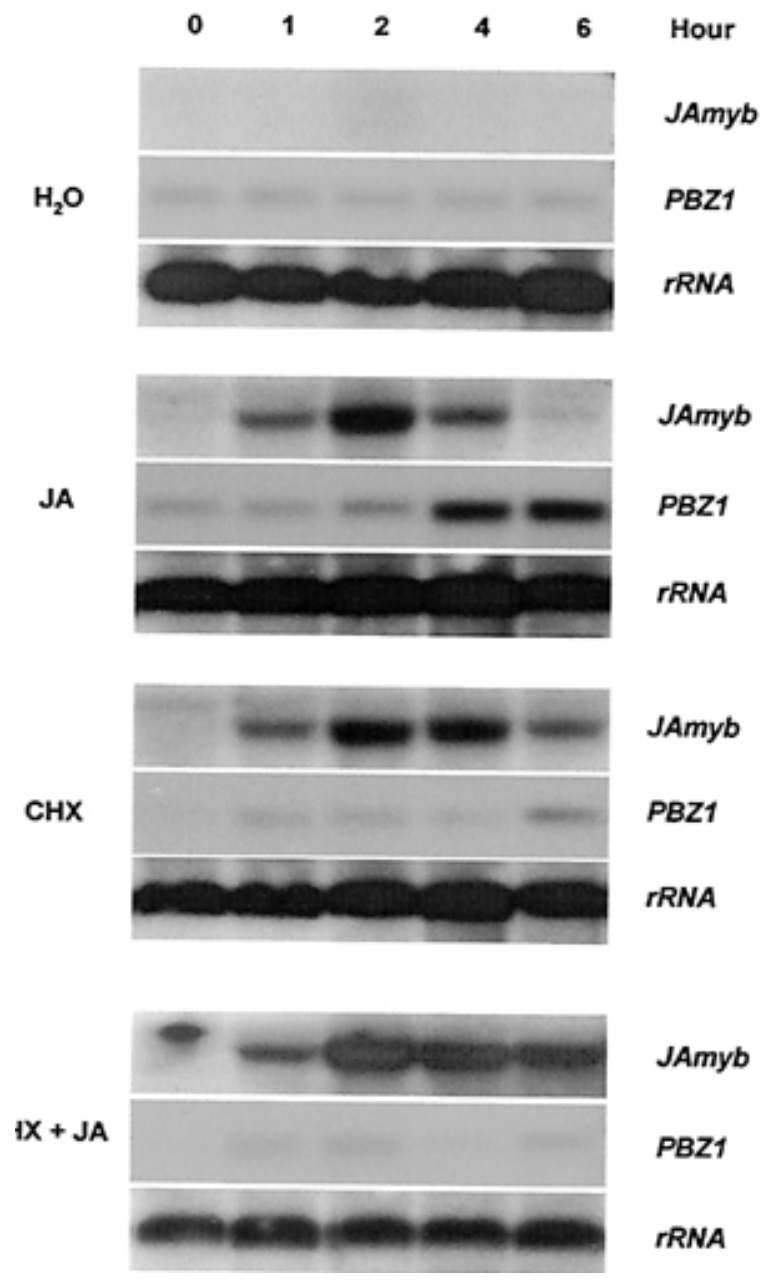

Fig. 8. Effect of cycloheximide on $J A m y b$ and $P B Z 1$ gene expression. Total RNAs were isolated from control leaves treated with $\mathrm{H}_{2} \mathrm{O}$, jasmonic acid (JA) $(0.1 \mathrm{mM})$ and cycloheximide $(\mathrm{CHX})(0.3 \mathrm{mM})$ as well as leaves that were pretreated with CHX for 30 min followed by treatment with JA $(0.1 \mathrm{mM})$ plus CHX $(0.3 \mathrm{mM})$. 
min before spraying with JA $(0.1 \mathrm{mM})$ plus CHX $(0.3 \mathrm{mM})$. Mechanical wounding was achieved by crushing rice leaves with a hemostat. Chemical treatments of cell-suspension cultures were performed by adding SA $(0.5 \mathrm{mM})$, JA $(0.02 \mathrm{mM})$, BTH $(0.05 \mathrm{mM})$, PBZ $(0.05 \mathrm{mM})$, or ABA $(0.03 \mathrm{mM})$ and subsequent samplings of suspension cells. All experiments were conducted at least twice.

Construction of a blast fungus-induced rice cDNA library.

Total RNAs were prepared by phenol-chloroform extraction from leaves of 2-week-old rice seedlings of Drew cultivar inoculated with avirulent or virulent blast isolates. Approximately $5 \mu \mathrm{g}$ of mRNA was obtained from $500 \mu \mathrm{g}$ of pooled total RNAs with the poly(A) mRNA isolation kit (Stratagene, La Jolla, CA, U.S.A.). The cDNA library was constructed with Stratagene's cDNA synthesis and ZAP Express vector kits, in accordance with the manufacturer's instructions. Firststrand cDNAs were synthesized from the blast-induced mRNAs. After removal of RNAs that bound to first-strand cDNAs by RNase $\mathrm{H}$ enzyme, second-strand cDNAs were synthesized with DNA polymerase. Subsequently, EcoRI adapters were ligated to the uneven termini of double-stranded cDNAs. The resulting adapted double-strand cDNAs were then digested with XhoI enzyme, producing directional cDNAs. After size fractionation with a drip column, cDNAs were precipitated and ligated to the ZAP express vector at $4{ }^{\circ} \mathrm{C}$ for $48 \mathrm{~h}$. The ligation products were packaged with Gigapack III gold packaging extract (Stratagene) and amplified in Escherichia coli strain XL-1 blue MRF'.

\section{Isolation and sequencing of the JAmyb cDNA.}

Two degenerate oligonucleotides corresponding to highly conserved regions in the DNA-binding domain of plant $\mathrm{Myb}$ proteins were synthesized: forward, 5'-AAGTCNTG(C/T) (A/C)GN(C/T)TI(A/C)GITGG-3'; and reverse, $5^{\prime}$-AT(C/T)TC 0GTTGTCNGTNC(G/T)NCC-3'. The cDNAs synthesized from blast-induced rice mRNAs were used as the template for PCR amplification. The amplified fragments (approximately $160 \mathrm{bp}$ ) were purified from a $2 \%$ agarose gel and cloned into pGEM-T Easy (Promega, Madison, WI, U.S.A.). After sequencing and Northern blot analysis, one of the PCR fragments was identified to be part of a blast- and JA-induced $m y b$ gene. This DNA fragment was used as a probe to isolate the corresponding full-length JAmyb cDNA by screening approximately $10^{6}$ plaques of the blast-induced cDNA library. The pBK-CMV phagemid carrying the JAmyb cDNA was then excised in vivo from the lambda ZAP Express vector with the ExAssist helper phage (Stratagene). Finally, the sequence of JAmyb cDNA was determined for both strands with the dideoxy chain termination method (automated sequencing service provided by University of Arkansas for Medical Science) and analyzed with Vector NTI Suite (InforMax, North Bethesda, MD, U.S.A.) and BLAST.

\section{DNA and RNA blot analysis.}

Total DNA was isolated from rice leaves by phenolchloroform extraction. Ten micrograms of genomic DNA was digested with EcoRI and HindIII, respectively; fractionated on a $1 \%$ agarose gel; and blotted onto a nylon membrane. To determine JAmyb transcript levels, total RNAs were isolated from leaf tissues with TRIzol reagent (Life Technologies,
Rockville, MD, U.S.A). Ten micrograms of total RNA was separated on a $1.2 \%$ agarose gel containing formaldehyde and then transferred onto a nylon membrane. Both DNA and RNA blots were hybridized with the $\left[\alpha-{ }^{32} \mathrm{P}\right]$ dCTP-labeled genespecific probe (550 to 1,343 bp of JAmyb). Hybridization and washing were conducted in accordance with the method of Church and Gilbert (1984).

\section{ACKNOWLEDGMENTS}

We thank J. Correll and F. Lee for providing blast isolates and Drew rice seeds, respectively. We also thank $\mathrm{T}$. Marchetti from the USDA/ARS and Texas A\&M University Agricultural Research and Extension Center (Beaumont, U.S.A.), for sending us the seeds of rice lesion mimic mutants. The Japanese Rice Genome Research Program and MAFF DNA Bank are gratefully acknowledged for providing the PBZ1 EST clone.

\section{LITERATURE CITED}

Bender, J., and Fink, G. R. 1998. A MYB homologue, ATR1, activates tryptophan gene synthesis in Arabidopsis. Proc. Natl. Acad. Sci. USA 95:5655-5660.

Chu, C. C., Wang, C. S., Sun, C. C., Hsu, C., Yin, K. C., and Chu, C. Y. 1975. Establishment of an efficient medium for another culture of right through comparative experiments on the nitrogen sources. Sci. Sinica 18:659-668.

Church, G. M., and Gilbert, W. 1984. Genomic sequencing. Proc. Natl. Acad. Sci USA 81:1991-1995.

Daniel, X., Lacomme, C., Morel, J. B., and Roby, D. 1999. A novel myb oncogene homologue in Arabidopsis thaliana related to hypersensitive cell death. Plant J. 20:57-66

Delaney, T. P., Uknes, S., Vernooij, B., Friedrich, L. and Weymann, K., Negrotto, D., Gaffney, G., Gut-Rella, M., Kessmann, H., Ward, E., and Ryals, J. 1994. A central role of salicylic acid in plant disease resistance. Science 266:1247-1249.

Dempsey, D., Shah, J., and Klessig. D. F. 1999. Salicylic acid and disease resistance in plants. Crit. Rev. Plant Sci. 18:547-575.

Dong, X. 1998. SA, JA, ethylene, and disease resistance in plants. Curr. Opin. Plant Biol. 1:316-323.

Gaffney, T., Friedrich, L., Vernooij, B., Negrotto, D., Nye, G., Uknes, S., Ward, E., Kessmann, H., and Ryals, J. 1993. Requirement of salicylic acid for the induction of systemic acquired resistance. Science 261:754-756.

Goodman, R. N., and Novacky, A. 1994. The Hypersensitive Reaction in Plants to Pathogens: A Resistance Phenomenon. American Phytopathological Society, St. Paul, MN, U.S.A.

Grotewold, E., Drummond, B. J., Bowen, B., and Peterson, T. 1994. The $m y b$-homologous $P$ gene controls phlobaphene pigmentation in maize floral organs by directly activating a flavonoid biosynthetic gene subset. Cell 76:543-553.

Gubler, F., Kalla, R., Roberts, J. K., and Kacobsen, J. V. 1995. Gibberellin-regulated expression of a $m y b$ gene in barley aleurone cells: Evidence for Myb transactivation of a high-pI alpha-amylase gene promoter. Plant Cell 7:1879-1891.

Harp, T. L., and Correll, J. C. 1998. Recovery and characterization of spontaneous, selenate-resistant mutants of Magnaporthe grisea, the rice blast pathogen. Mycologia 90:954-963.

Hoeren, F. U., Dolferus, R., Wu, Y., Peacock, W. J., and Dennis, E. S. 1998. Evidence for a role for AtMYB2 in the induction of the Arabidopsis alcohol dehydrogenase gene $(A D H 1)$ by low oxygen. Genetics 149:479-490.

Iturriga, G., Leyns, L., Villegas, A., Gharaibeh, R., Salamini, F., and Bartels, D. 1996. A family of novel $m y b$-related genes from the resurrection plant Craterostigma plantagineum are specifically expressed in callus and roots in response to ABA or desiccation. Mol. Gen. Genet. 32:707-716.

Jin, H., and Martin, C. 1999. Multifunctionality and diversity within the plant MYB-gene family. Plant Mol. Biol. 41:577-585.

Kranz, H. D., Denekamp, M., Greco, R., Jin, H., Leyva, A., Meissner, R. C., Petroni, K., Urzainqui, A., Bevan, M., Martin, C., Smeekens, S., 
Tonelli, C., Paz-Ares, J., and Weisshaar, B. 1998. Towards functional characterization of the members of the R2R3-MYB gene family from Arabidopsis thaliana. Plant J. 16:263-276.

Lee, J., Parthier, B., and Lobler, M. 1996. Jasmonate signaling can be uncoupled from abscisic acid signaling in barley: Identification of jasmonate-regulated transcripts which are not induced by abscisic acid. Planta 199:625-632.

Lipsick, J. S. 1996. One billion years of Myb. Oncogene 13:223-235.

Marchetti, M. A., Bollich, C. N., and Uecker, F. A. 1983. Spontaneous occurrence of the Sekiguchi lesion in two American rice lines: Its induction, inheritance, and utilization. Phytopathology 73:603-606.

Magaraggia, F., Solinas, G., Valle, G., Giovinazzo, G., and Coraggio, I. 1997. Maturation and translation mechanisms involved in the expression of a $m y b$ gene of rice. Plant Mol. Biol. 35:1003-1008.

Martin, C., and Paz-Ares, J. 1997. MYB transcription factors in plants. Trends Genet. 13:67-73.

Meissner, R. C., Jin, H., Cominelli, E., Denekamp, Marten., Fuertes, A., Greco, R., Kranz, H. D., Penfield, S., Petroni, K., Urzainqui, A., Martin, C., Paz-Ares, J., Smeekens, S., Tonelli, C., Weisshaar, B., Baumann, E., Klimyuk, Marillonnet, S., Patel, K., Speulman, E., Tissier, A. F., Bouchez, D., Jones, J. J. D., Pereira, A., Wisman, E., and Bevan, M. 1999. Function search in a large transcription factor gene family in Arabidopsis: Assessing the potential of reverse genetics to identify insertional mutations in R2R3 MYB genes. Plant Cell 11:1827-1840.

Menke, F. L. H., Champpion, J. W. K., and Memelink, J. 1999. A novel jasmonate-and elicitor-responsive element in the periwinkle secondary metabolite biosynthetic gene Str interacts with a jasmonate- and elicitor-inducible AP2-domain transcription factor, ORCA2. EMBO J. 18:4455-4463.

Midoh, N., and Iwate, M. 1996. Cloning and characterization of a probenazole-inducible gene for an intracellular pathogenesis-related protein in rice. Plant Cell Physiol. 37:9-18.

Moyano, E., Martinez Gracia, J. F., and Martin, C. 1996. Apparent redundancy in $m y b$ gene function provides gearing for the control of flavonoid biosynthesis in Antirrhinum flowers. Plant Cell 8:15191532.

Noda, K.-I., Glover, B. J., Linstead, P., and Martin, C. 1994. Flower colour intensity depends on specialized cell shape controlled by a Myb-related transcription factor. Nature 369:661-664.

Oh, I. H., and Reddy, E. P. 1999. The myb gene family in cell growth, differentiation and apoptosis. Oncogene 18:3017-3033.

Oppenheimer, D. G., Herman, P. L., Sivakumaran, S., Esch, J., and Marks, M. D. 1991. A myb gene required for leaf trichome differentiation in Arabidopsis is expressed in stipules. Cell 67:483-493.

Paz-Ares, J., Ghosal, D., Wienand, U., Peterson, P. A., and Saedler, H. 1987. The regulatory $c l$ locus of Zea mays encodes a protein with homology to $m y b$ proto-oncogene products and with structural similarities to transcriptional activators. EMBO J. 1:3553-3558.

Penninckx, I. A. M. A., Eggermont, K., Terras, F. R. G., Thomma, B. P. H. J., De Samblanx, G. W., Buchaia, A., Metraux, J. P., Manners, J. M., and Broekaert, W. F. 1996. Pathogen-induced systemic activation of a plant defensin gene in Arabidopsis follows a salicylic acidindependent pathway. Plant Cell 8:2309-2323.

Pieterse, C. M., and Van Loon, L. C. 1999. Salicylic acid-independent plant defense pathways. Trends Plant Sci. 4:52-58.

Reymond, P., and Farmer, E. E. 1998. Jasmonate and salicylate as global signals for defense gene expression. Curr. Opin. Plant Biol. 1:404-411.
Rosinski, J. A., and Atchley, W. R. 1998. Molecular evolution of the Myb family of transcription factors: Evidence for polyphyletic origin. J. Mol. Evol. 46:74-83.

Rushton, P. J., and Somassich, I. E. 1998. Transcriptional control of plant genes responsive to pathogens. Curr. Opin. Plant Biol. 1:311315.

Ryals, J. A., Neuenschwander, U. H., Willits, M. G., Molina, A., Steiner, H. Y., and Hunt, M. D. 1996. Systemic acquired resistance. Plant Cell 8:1809-1819.

Sablowski, R. W. M., Moyano, E., Culianez Macia, F. A., Schuch, W., Martin, C., and Bevan, M. 1994. A flower-specific Myb protein activates transcription of phenylpropanoid biosynthetic genes. EMBO J. 13:128-137.

Schweizer, P., Buchala, A., Dudler, R., and Métraux, J.-P. 1998. Induced systemic resistance in wounded rice plants. Plant J. 14:475-481.

Takahashi, A., Kawasaki, T., Henmi, K., Shii, K., Kodama, O., Satoh, H., and Shimamoto, K. 1999. Lesion mimic mutants of rice with alterations in early signaling events of defense. Plant J. 17:535-545.

Tamogami, S., Rakwal, R., and Kodama, O. 1997. Phytoalexin production by amino acid conjugates of jasmonic acid through induction of naringenin-7-O-methyltransferase, a key enzyme on phytoalexin biosynthesis in rice (Oryza sativa L.). FEBS Lett. 401:239-242.

Tamagnone, L., Merida, A., Parr, A., Mackay, S., Culianez-Macia, F. A., Roberts, K., and Martin, C. 1998. The AmMYB308 and AmMYB330 transcription factors from Antirrhinum regulate phenylpropanoid and lignin biosynthesis in transgenic tobacco. Plant Cell 10:135-154.

Thomma, B. P. H. J., Eggermont, K., Penninckx, I. A. M. A., MauchMani, B., Vogelsang, R., Cammue, B. P. A., and Broekaert, W. F. 1998. Separate jasmonate-dependent and salicylate-dependent defense-response pathways in Arabidopsis are essential for resistance to distinct microbial pathogens. Proc. Natl. Acad. Sci. USA 95:1510715111.

Urao, T., Yamaguchi Shinozaki, K., Urao, S., and Shinozaki, K. 1993. An Arabidopsis myb homolog is induced by dehydration stress and its gene product binds to the conserved MYB recognition sequence. Plant Cell 5:1529-1539.

Van der Fits, L., and Memelink, J. 2000. ORCA3, a jasmonateresponsive transcriptional regulator of plant primary and secondary metabolism. Science 289:295-298.

Vijayan, P., Shockey, J., Andre Levesque, C., James Cook, R., and Browse, J. 1998. A role for jasmonate in pathogen defense of Arabidopsis. Proc. Natl. Acad. Sci. USA 95:7209-7214.

Waites, R., Selvadurai, H. R. N., Oliver, I. R., and Hudson, A. 1998. The PHANTASTICA gene encodes a MYB transcription factor involved in growth and dorsoventrality of lateral organs in Antirrhinum. Cell 93:779-789.

Weston, K. 1998. Myb proteins in life, death and differentiation. Curr. Opin. Genet. Dev. 8:76-81.

Xie, D. X., Feys, B. F., James, S., Nieto-Rostro, M., and Turner, J. G. 1998. Coll: An Arabidopsis gene required for jasmonate-regulated defense and fertility. Science 280:1091-1094.

Yang, Y., and Klessig, D. F. 1996. Isolation and characterization of a tobacco mosaic virus-inducible myb oncogene homolog from tobacco. Proc. Natl. Acad. Sci. USA 93:14972-14977.

Yang, Y., and Qi, M. 2000. Potential role of salicylic acid in maintaining redox balance of rice plants. (Abstr.) Phytopathology 90:S86.

Yang, Y., Shah, J., and Klessig, D. F. 1997. Signal perception and transduction in plant defense responses. Genes Dev. 11:1621-1639. 